\title{
Power Flow Analysis of Distribution Systems with Large-Scale Wind and Conventional Energy Generation
}

\author{
A. González ${ }^{2}$, A. Madrazo ${ }^{1}$, R. Robles ${ }^{1}$, R. Domingo ${ }^{1}$, M. Mañana ${ }^{1}$, A. Arroyo ${ }^{1}$ and M.A.Cavia ${ }^{1}$ \\ ${ }^{1}$ Department of Electrical and Energy Engineering \\ University of Cantabria \\ Avda. Los Castros s/n, 39005Santander (Spain) \\ Phone number:+0034 942201378, e-mail: mananam@unican.es \\ ${ }^{2}$ E.On Distribución, S.L. \\ C/ Real Consulado, s/n (Pol. Candina) \\ 39011 SANTANDER
}

Phone number:+0034 942246000 (ext. 2475), e-mail: antonio.gonzalez@eon.com

\begin{abstract}
.
This paper is devoted to the development of a methodology suitable to be used to determine the impact of the grid integration of wind farms in distribution networks that are also supplied with other classical generation facilities based on thermal and hydraulic energy.
\end{abstract}

The methodology is based on an automated analysis system that varies the level of the electric generation for both the hydraulic and thermal generators by using PSS, Phyton and Matlab. The user can define multiple scenarios considering wind, thermal and hydraulic generators so the line capacity can be computed and compared in order to know where the system bottleneck is located and which situations occur.

All the results computed can be analysed in a single or compared way by using tables and plots and considering the static rate of the distribution lines.

The developed system can also be applied to the computation of the sensitivity of the power flow to the variation of the parameters that define the power system.

\section{Key words}

Wind Energy, Power Flow, Grid Integration.

\section{Introduction}

The growing use of wind energy systems in the Spanish grid and their typical location far away from the transport network is leading to distribution networks that are closer to their limits. Nowadays, it is not unusual that some percentage of the wind farms have to be stopped because the distribution network reaches its maximum static capacity.

Solving this problem requires: (i) to build/re-power new electric infrastructures that increase the capacity of the distribution network and/or (ii) to increase the rate of the power lines by using dynamic rates (ampacity).

This research work focuses on the development of a methodology and a set of tools suitable to evaluate the effects of several scenarios of generation in the behaviour of the distribution networks, especially those that are close to wind farms. It will also be considered the effect of other generation technologies such as Thermal and Hydraulic (see Fig.1). The methodology and software developed provides useful information that help to the Distributor System Operator (DSO) to determine the hydraulic and thermal generation maximum level that can be generated in order to avoid restrictions with the level of wind power in each moment.

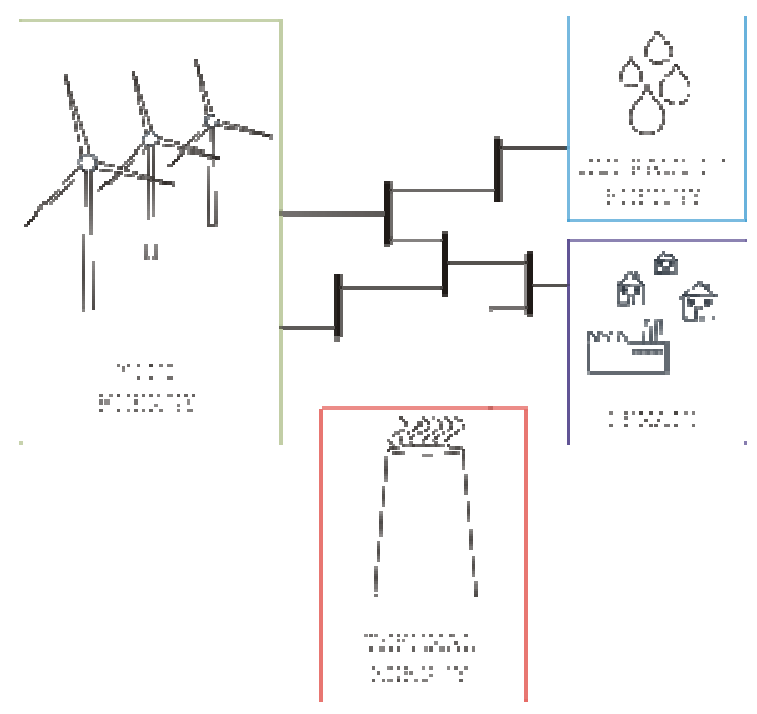

Figure1. Grid Scheme. 
Wind generation will always take percent values from 10 to 100 in all cases while hydraulic and thermal generation remaining fixed. Depending on the number of thermal and hydraulic scenarios, multiple simulations will be performed. Table I summarizes the proposed methodology.

Table I. Analyzed Cases.

\begin{tabular}{|c|c|c|c|}
\hline & $\begin{array}{l}\text { Fixed } \\
\text { Value }\end{array}$ & $\begin{array}{c}\text { Variable } \\
\text { Value }\end{array}$ & \\
\hline 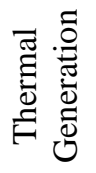 & $0 \%-100 \%$ & \multirow{2}{*}{$10 \%-100 \%$} & \multirow{2}{*}{ 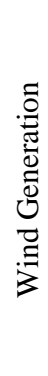 } \\
\hline 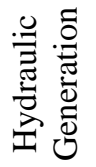 & $0 \%-100 \%$ & & \\
\hline
\end{tabular}

The cases that are summarized in Table I can be expanded to a variable number of simulations in an automated way that can be set by the user.

This approach can be useful in order to determine the bottleneck or the most critical points of the distribution network.

In addition, this approach can be used in contingency analysis (CA). In this case, the software uses a heuristic approach to study several scenario simulations in order to evaluate the impacts on the distributions system of different problems. From a general point of view, problems like the failure or loss of parts of the power systems (e.g. transformers of transmission lines). These kinds of failures are considered unplanned "outages". The proposed methodology can be used to:

- Evaluate the impact of the failures.

- Compute any overloads produce by the failures.

From the point of view of users, CA is basically a preview analysis tool that can be used in both off-line and on-line analysis. This tool helps operators to know the behavior of the system in uncommon situations.

\section{Results}

Fig.4 shows an example of one of the plots that can be generated. In this example, the level of charge in several lines is compared considering the same generation scenario $(0 \%$ of nominal thermal capacity and $50 \%$ of nominal hydraulic capacity).

It can be observed that there are two lines exceeding their rated capacity at around $60 \%$ of wind generation (pink and black lines). It can be also seen that the other lines are less sensitive to the increase of wind generation, and can work below the rated capacity for all possible wind generation scenarios, especially in the case of yellow and sky blue lines.

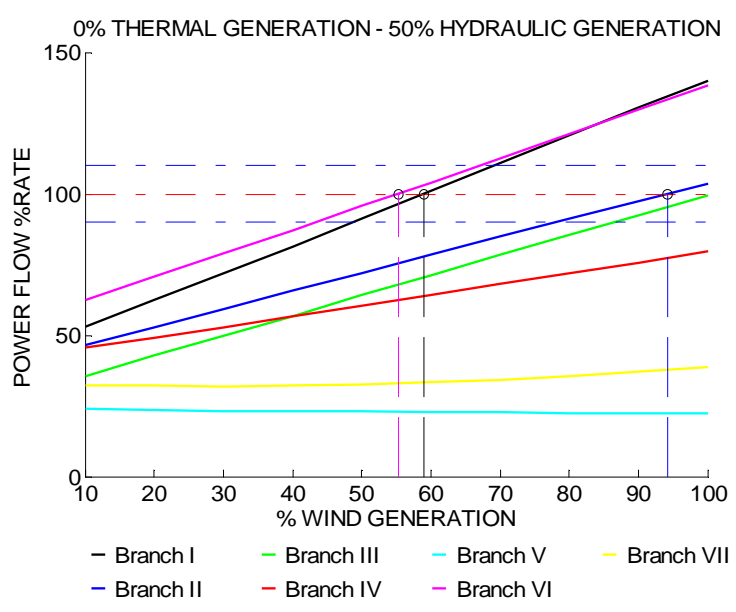

Figure 4. Branches in Same Scenario

In addition, Fig. 5 shows the results only for the branch I. In this example, each curve represents the power flow as a percentage of the nominal line capacity (rate) for several levels of wind power and for a constant level of thermal and hydraulic power.

In this example it is also possible to notice that the worst scenario for wind generation is reached by the green curve (40\% Thermal and $40 \%$ Hydraulic power), and the best scenario that allows to integrate more wind energy is for the yellow curve (10\% Thermal power and Hydraulic power).

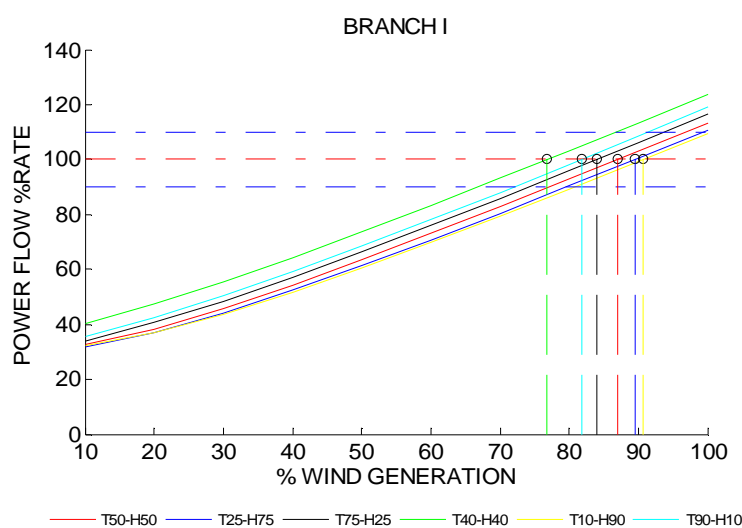

Figure 5. Branch behavior in several scenarios .

The results shown in figure 5 are conditioned by the topology of the analyzed network, because in this case the hydraulic and thermal generation plants are connected directly to the transport network of $400 \mathrm{kV}$ and the generated power doesn't use the distribution network. For this reason, the effects of different thermal and hydraulic generation scenarios are almost not observed in distribution network such as the one that it is indicated in Figure 5.

Fig. 6 shows the result of the contingency analysis of the type $\mathrm{N}-1$. In this example the branch number II is open and the figure shows the rate in a specific scenario for the rest of branches. 


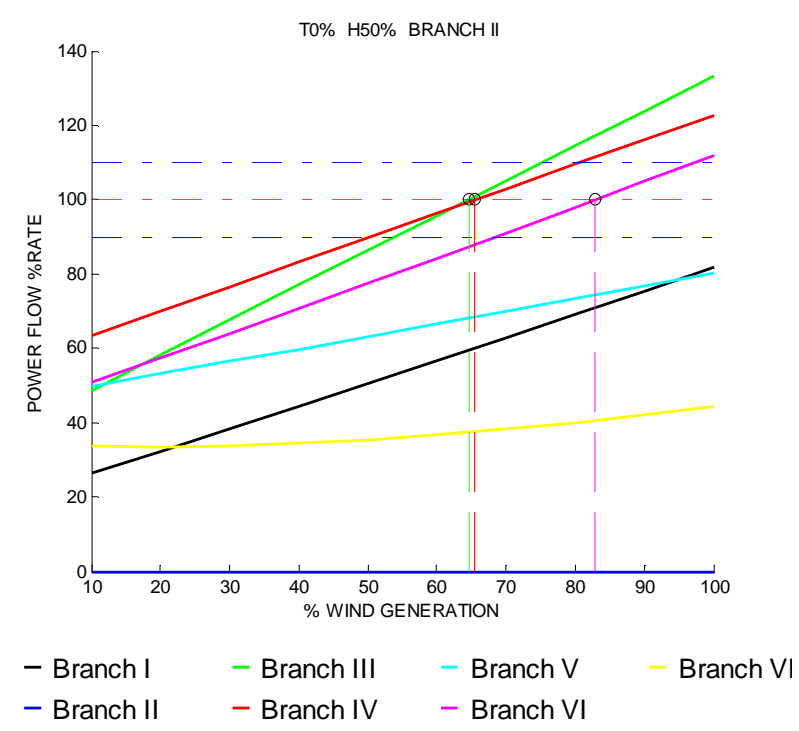

Figure 6. Contingency analysis.

\section{Conclusions}

This system works with any network modeled in PSS and can be improved to extend the type of analysis that can be performed because of the integration between PSS, Python and Matlab.

In this work the developed system has been applied basically to study the effects of the wind power penetration in the level of charge of several lines of a distribution network.
It can be also applied to the study of the effects of the generation level with other generation technologies maintaining fixed the wind power generation.

It is possible to extend the program to the contingence analysis in an easy way considering $\mathrm{N}-1$ or $\mathrm{N}-2$ scenarios.

\section{Acknowledgement}

This work was supported by the Spanish Government under the $\mathrm{R}+\mathrm{D}$ initiative INNPACTO with reference IPT2011-1447-920000.

\section{References}

[1] S.Heier, Grid Integration of Wind Energy Conversion Systems. Wiley, 2006.

[2] SIEMENS. PSS/E 32.0.5 Program Operation Manual, October 2010.

[3] The Python Language Reference. (http://docs.python.org/ $2 /$ reference/)

[4] Matlab User's Guide.The Mathworks.

[5] Ben Pilato, BryanLake, Nick San Pietro, Waylon Cash, Andy Keller and VahramAtephany, Creation of a Power Flow Study. Master's thesis, Department of Electrical and Computer Engineering.Colorado University.

[6] Javier Vaquerizo Virto. Probabilidad de sobrecargas en Líneas de Transporte Debidas a la Incertidumbre de la Producción Eólica (In Spanish). Tesis de Master. Universidad Carlos III de Madrid Escuela Politécnica Superior, 2009. 